\title{
Usufruto: do Direito Romano aos Direitos Português e Brasileiro
}

Raimundo Chaves Neto

Especialista em Direitos Humanos e em História do Direito pela Universidade de Coimbra (Portugal). Mestrando em Direito pela Universidade de Coimbra. neto@conego.com.br

Sumário: Introdução. 1. Definição de usufruto. 2. Constituição. 3. Regime Jurídico. 4. Extinção. 5. Tutela Jurídica. 6. Usufruto nos direitos português e brasileiro. Conclusões. Referências.

Resumo: O presente artigo, produzido em torno da romanística, apresentará e analisará brevemente os aspectos históricos e jurídicos referentes ao instituto do usufruto. Será realizada sucinta abordagem desde a sua origem e desenvolvimento no direito romano até uma também breve referência aos direitos português e brasileiro.

Palavras-chave: Usufruto. Direito Romano. Direito Português. Direito Brasileiro.

\section{INTRODUÇÃO}

O estudo do direito romano representa um admirável instrumento de educação jurídica. Vê-se no Código Civil de 1916 que, dos seus 1.807 artigos, 1.445 originaram-se na cultura romana, conforme analisaremos. No atual código de 2002, a tradição romana também é mantida.

O usufruto tem como característica constituir-se um direito real de gozo, não exclusivo, limitado, temporário, e deve incidir sobre uma res alheia.

A natureza jurídica do direito de usufruto constitui-se em vexata questio para a romanística.

O presente artigo será dividido em seis partes. Inicialmente, o texto versará sobre a identificação do usufruto dentre os direitos reais, tornando-se necessário realizar a sua definição, dissertar a respeito da origem romana e da natureza jurídica e da sua aplicação durante os diversos períodos de Roma.

A segunda parte será desenvolvida em torno dos modos de constituição do 
usufruto: contrato, testamento, usucapião, além de outros. O regime jurídico será abordado na fase seguinte. Já a quarta parte analisará as diversas formas de extinção do usufruto. A seguir, serão exploradas as formas de tutela jurídica.

Na derradeira parte realizaremos comentários e críticas relativos à aplicação do usufruto nos direitos português e brasileiro.

\section{DEFINIÇÃO DE USUFRUTO}

\subsection{NOÇÃO}

A definição do jurisconsulto Paulus (CRUZ, 1984, p. 399) nos informa que o usufruto (usus fructus) representa um "direito de usar e desfrutar uma coisa alheia, respeitando a sua substância”. O presente conceito poderá não ter sido construído durante o período clássico, entretanto a opinião dominante é de que esta conceituação realmente date desse período.

O usus fructus está inserido dentre os direitos reais e apresenta-se como inalienável e condicionado ao limite temporal, diferentemente de outros institutos semelhantes, como enfiteuse, condomínio, arrendamento e fideicomisso.

\subsection{ORIGEM HISTÓRICA}

O presente instituto surgiu posteriormente às servitutes, embora seja considerado servitutes personarum (SANTOS JUSTO, 1997, p. 175). O surgimento do usus fructus data, provavelmente (IGLESIAS, 1953, p. 250), do século II a.C. e fora criado pela iurisprudentia com o objectivo de proteger a mulher que atingisse a viuvez. Nesta fase da história de Roma, os matrimônios passaram a ser celebrados sob uma nova concepção sine manu em substituição à cum manu (SANTOS JUSTO, 2008, p. 3233). Ou seja, a mulher não mais ingressava na família do marido, portanto não poderia constituir-se como herdeira deste. Então, o que na prática acontecia era que enquanto o marido estivesse vivo, a uxor gozava dos bens que o marido lhe disponibilizasse. Entretanto, com o falecimento deste, aquela ingressava numa vida de penúria econômica (o que provocava inúmeras vezes o ingresso da viúva a uma vida de prostituição e mendicância). No intuito de evitar tal situação, antes de falecer, o marido nomeava a esposa como usufructuarius dos bens que ele julgasse necessários para a subsistência da viúva. Portanto, a princípio, o usus fructus tinha caráter alimentício (MOREIRA ALVES, 2007, p. 346). Vale ressaltar que a lista dos beneficiários, com o tempo, passou a contemplar também os familiares do paterfamilias que não pudessem constar no rol dos herdeiros (SANTOS JUSTO, 1997, p. 350).

\subsection{CARACTERÍSTICAS}


Apresenta o referido instituto algumas características que o distinguem de outros direitos reais (SANTOS JUSTO, 1997, p. 351-353). A primeira delas é representar um direito real de gozo, com o qual o usufrutuário frui das utilidades e frutos de um bem, de propriedade de outrem, no entanto é intransmissível. Em seguida temos o princípio da não exclusividade da propriedade objeto do usufruto, pois a res estará subdividida em usufruto e propriedade. Apresenta-se como um direito limitado, pois o usufrutuário não poderá alterar a substância e a destinação econômica da propriedade. A característica da temporariedade, determina que o titular é, individualmente, considerado intuitu personae, por isso o direito se extingue, no mais tardar, com a morte do usufrutuário (no caso de usufruto vitalício). Poderá também ser constituído por certo prazo (usufruto temporário), mas a morte do titular extingue-o mesmo antes do vencimento do prazo estabelecido. Caso o titular fosse pessoa jurídica, o usufruto extinguia-se depois de decorridos 100 anos, pois este era considerado como o limite máximo de duração da vida humana. O presente direito real deverá recair sobre ius in re aliena.

Os sujeitos de direito do usufruto denominados fructuarius ou usufructuarius poderiam ser pessoas fisicas e jurídicas. O proprietário da res tida sob usufruto era denominado senhor da dominus proprietatis ou senhor da propriedade e nudus dominus ou nu-proprietário (MOREIRA ALVES, 2007, p. 346). Conforme as características supracitadas inerentes ao usufruto, temos que o usufruto consiste em usar e desfrutar uma ius in re aliena sem provocar na referida coisa alterações substanciais. Ora, há, pois, nesta característica um pressuposto de restringir o instituto apenas a coisas inconsumíveis, pois estendido a coisas consumíveis, como preservar a sua substância?

\subsection{NATUREZAJURÍDICA}

Diversos aspectos do direito romano apresentam questões controversas que dividem a romanística, dentre elas também encontra-se determinar a natureza jurídica do usus fructus durante o período arcaico (CRUZ, 1984, p. 43)르 até o clássico (CRUZ, 1984, 46) $)^{2}$. Kaser (IGLESIAS, 1953, p. 265), por exemplo, afirma que este representava um autêntico direito de propriedade, porém limitado aos frutos. Já Riccobono (IGLESIAS, 1953, p. 266) defende que o usufruto representava "uma parcela do direito de propriedade", ou seja o fructuarius era o proprietário do direito ao gozo da coisa, porém não era dotado de poderes para dispor dela. Perozzi (IGLESIAS, 1953, p. 266) leciona que o referido direito real seria um direito de propriedade revestido

\footnotetext{
1 Período do Direito Romano compreendido entre a provável fundação de Roma (753 a. C.) ao ano 130 a. C.

2 Período do Direito Romano compreendido entre o ano 130 a. C. e 230 d. C.
} 
de temporariedade sobre coisa que teria sua propriedade perpétua pertencente a outra pessoa. Entendemos que no período clássico o ususfructus já se distinguia do direito de propriedade e apresentava-se como um direito sobre coisa alheia. Apenas no direito justinianeu, o usufruto e os demais direitos reais semelhantes foram classificados como servidões pessoais.

\section{CONSTITUIÇÃO}

O usufruto pode ser constituído em favor de uma pessoa ou de várias.

Durante o período clássico, assim como as servidões prediais, o supracitado instituto era constituído iure civile conforme: legado per vindicationem, adiudicatio nas ações divisórias; in iure cessio; e deductio em mancipatio.

Quanto aos fundi (imóveis provinciais), o usufruto era constituído através de pactiones et stipulationes.

Importante mudança ocorreu no direito justinianeu, pois com o fim da in iure cessio, as pactiones et stipulationes passaram a fazer as vezes daquela na celebração do usufruto. Modificou-se, também, a deductio, que passou a ser realizada por meio da traditio.

$\mathrm{O}$ usus fructus passa a poder ser constituído pela longi temporis praescriptio (fundamentada na inação do proprietário). Além de todas estas mudanças, são criados, por determinação legal, novas formas ex lege (SANTOS JUSTO, 1997, p. 196-197) de constituição de usufruto.

\section{REGIME JURÍDICO}

O usufructuarius, apesar de ser titular de um verdadeiro direito real, constitui-se mero detentor de uma ius in re aliena, podendo apenas usar e fruir a coisa, cuidando da mesma como se sua fosse, sem alterar, entretanto, sua substância ou destinação econômica. Deverá agir, portanto, como um bonus paterfamilias.

Ainda no período clássico, o usufrutuário era totalmente impedido de realizar alterações, inclusive melhoramentos na res. Entretanto, no período pós-clássico (CRUZ, 1997, p. 48) ${ }^{3}$, foram introduzidas modificações jurídicas que ampliavam os poderes do usufrutuário.

Movidas pelas crises econômicas da época, as alterações legais previam, inclusive, que "o usufrutuário poderia cultivar a terra, abrir novas minas e, de uma maneira geral, possuía a faculdade de melhorar a coisa" (IGLESIAS, 1953, p. 269).

\footnotetext{
${ }^{3}$ Período do Direito Romano compreendido entre o ano 230 d. C. e 530 d. C.
} 
Aspecto interessante era que a res com a qual era celebrado o usufruto não conferia ao usufrutuário o direito sobre uma ilha formada no rio que atravesasse o terreno recebido, pois a fruição alcançava apenas o bem originário.

Quanto aos filhos das escravas (no caso de servus fructuarius), estes não seriam considerados frutos (nem naturais, tampouco civis), pois os jurisconsultos romanos determinavam como frutos daquela natureza apenas as crias dos animais ${ }^{4}$.

O direito de usufruto apresenta-se para o usufrutuário como intransmissível a terceiros, porém o exercício deste poderá ser cedido, mas cessará com a morte daquele, mesmo que estes ainda estejam vivos.

O usufructuarius não terá direito ao tesouro como proprietário, mas apenas como achador em res aliena.

Dentre as obrigações do usufrutuário (que possui a liberalidade de uso e fruição do bem), em primeiro lugar estava conservar a res em bom estado, pois todo cuidado, característico do bom paterfamilias deveria ser dispensado para manter a res a salvo de qualquer perigo que pudesse ser previsto e sanado.

Fazia parte das obrigações também pagar impostos e encargos; prestar cautio usufructuaria como garantia ao constituir o usufruto da res de que a usará como um bom paterfamilias e a devolverá no estado de conservação em que recebeu.

\section{EXTINÇÃO}

Ocorre extinção através de: renúncia do usufrutuário; consolidatio (também conceituada como confusão ou reunião na mesma pessoa, dos atributos de nu-proprietário e usufructuarius); destruição ou alteração da substância ou da finalidade econômica da coisa, embora com o passar do tempo a alteração da substância da coisa tenha passado também a significar a destinação econômica desta.

Poderia, ainda, ocorrer extinção através de: non usus da coisa; ocorrência do termo, ou seja, fim do prazo estabelecido para ocorrência do usufruto; morte do usufrutuário; ou se o usufrutuário sofresse capitis deminutio, que a princípio poderia ser por qualquer uma das três (mínima, média e máxima), mas no período justinianeu passou a ser apenas pela ocorrência das duas últimas.

\footnotetext{
4 Temos a opinião de que os jurisconsultos, sob a justificativa de não querer animalizar as escravas, acabavam por beneficiar exclusivamente os proprietários, pois os filhos destas (dadas em usufruto) seriam sempre do nu-proprietário.
} 


\section{TUTELA JURÍDICA}

Os direitos do usufrutuário são tutelados na esfera judicial por uma actio in rem (ação real), designada vindicatio ususfructus, também nomeada pelas fontes como petitio usufructus. Inicialmente, a presente actio só poderia ser intentada pelo usufructuarius contra o proprietário, porém no final do período clássico a iurisprudentia determinou que a mesma pudesse ser utilizada contra qualquer pessoa que turbasse o exercício do usus fructus. Já no direito justinianeu, a ação tutelatória passou a ser denominada confessoria ususfructus.

Além dos instrumentos tutelatórios supracitados, podia ainda o usufrutuário opor contra o proprietário uma exceptio usufructus; exigir do vizinho a prestação de uma cautio damni infecti; realizar denunciação de obra nova; reivindicar servidão; fazer a demarcação e demandar com a actio aquaepluviaearcendae. Vale ressaltar que, no período clássico, o usufruto também era tutelado pelo pretor, mediante interditos possessórios (uti possidetis e unde vi).

Para prevenir-se contra perturbações futuras podia solicitar a cautio de non amplius turbando.

O proprietário goza do direito de tudo que não for caracterizado fruto, ou seja: à metade do tesouro, aos animais mortos e às árvores arrancadas pela natureza. Além do mais, pode também exigir uma prestação-caução de dano infecto. Pode ainda opor ações de tutela da sua propriedade (como danos causados, furto, reparação de ofensa a escravos e capturar estes em caso de cometerem algum crime). Dentre outros direitos, o dominus podia, ainda, transformar o imóvel, objecto do usufruto, em local sagrado, bastando que o usufrutuário concordasse.

\section{USUFRUTO NOS DIREITOS PORTUGUÊS E BRASILEIRO}

O atual Código Civil Português consagra no Título III do seu Livro III (Direito das Coisas) os capítulos I a V (especificamente os artigos $1439^{\circ}$ a $1483^{\circ}$ ) o usufruto e constitui-se como instrumento jurídico que apresenta importantes marcas romanas, das quais citaremos algumas.

Inicialmente, temos no artigo $1439^{\circ}$ a definição de usufruto como "o direito de gozar temporária e plenamente uma coisa ou direito alheio, sem alterar a sua forma ou substância. A presente noção traduz o texto de Paulus encontrado no Digesto. Os modos de constituição (artigo $1440^{\circ}$ ) e extinção (artigo $1476^{\circ}$ ) também acompanham a doutrina romana. Também a previsão de simultaneidade e de sucessividade da constituição de pessoas como usufrutuárias do artigo $1441^{\circ}$ mantiveram a tradição romana. Inclusive, o direito de acrescer (artigo $1442^{\circ}$ ) fundamenta-se na legislação romana.

No artigo $1443^{\circ}$, apesar de prever o prazo de trinta anos para a duração máxima do usufruto para pessoas colectivas (enquanto no direito romano determinava cem 
anos), permanece no restante do texto fiel às ideias romanas. Assim como o artigo $\left(1444^{\circ}\right)$ que regula o trespasse a terceiro.

Os direitos do usufrutuário relacionados no artigo $1445^{\circ}$ e as obrigações dos artigos $1468^{\circ}$ a $1475^{\circ}$ permanecem sob a égide romana. $\mathrm{O}$ artigo $1470^{\circ}$, entretanto, apresenta-se como exceção à fórmula romana, pois não extingue, automaticamente, o direito de usufruto pela recusa de prestar caução.

Portanto, na parte fundamental do usufruto português, concluímos que nele são inegáveis as influências do direito romano.

O Código Civil Brasileiro (CCB) de 2002 consagra no Título VI do seu Livro III (Direito das Coisas) os capítulos I a IV (especificamente os artigos 1390 a 1411) o usufruto e constitui-se como instrumento jurídico que apresenta importantes marcas, não só romanas, mas também portuguesas.

Assim como no direito romano, determina o artigo 1393 que o direito de usufruto não poderá ser vendido, mas prevê que o exercício do usufruto poderá ser cedido de forma gratuita ou onerosa. O benefício do usufruto somente poderá alcançar o seu titular, não se transmitindo aos seus herdeiros por mortis causa.

Relativamente aos bens móveis, inclusive os semoventes, estes podem ser objeto do usufruto. Portanto, conforme o artigo 1397 do CCB e do sistema jurídico romano, é concedido ao usufrutuário o direito de fruir de tudo que é gerado pelo rebanho: leite, lã, trabalho motor do animal, os filhotes etc.

A obrigatoriedade da prestação de caução no direito brasileiro, assim como no romano também é dispensada ao doador que se reservar o usufruto da res doada.

Porém, há uma divergência surgida no Código Brasileiro de 2002 perante o direito romano que não havia no Código de 1916. Trata-se do quase usufruto ou usufruto impróprio (aquele que recai sobre coisas consumíveis e fungíveis). No Brasil, em regra, o usufruto recai somente sobre bens inconsumíveis, ou seja, os bens que não perdem a substância pelo uso. O Código de 1916, no seu artigo 726, previa o usufruto sobre bens consumíveis. Porém o CGB de 2002 não acolheu o referido artigo, mas admitiu que o usufruto alcance as coisas acessórias e os acrescidos consumíveis do bem que é objeto de usufruto (artigo 1392, $\S 1^{\circ}$ ).

Apesar de uma pequena divergência (quase desprezível), vê-se, claramente a influência romana e até mesmo a portuguesa no direito brasileiro (caso do prazo de 30 anos do artigo $1443^{\circ}$ do Código Português e do artigo 1.410, inciso II do Código Brasileiro).

\section{CONCLUSÕES}

$\mathrm{O}$ presente estudo resultou da pesquisa pelas fontes romanas, portuguesas e brasileiras a respeito do usufruto. Entretanto, encaramos o mesmo como inacabado, pois ainda há muito que ser visto e escrito. 
Desde o princípio, percebemos a importância do estudo do Direito Romano na formação do jurista, tanto brasileiro quanto português, assim como de todos os juristas latinos. O usufruto é um tema atual, debatido tanto em países europeus como em países latino-americanos, principalmente no Brasil.

O sistema jurídico romano constitui-se como base do Direito de inúmeros países. Historicamente, podemos citar um período de "quase-esquecimento" do direito romano (pós Roma Imperial). Entretanto, a partir do seu ressurgimento, com uma força monumental, através da Escola dos Glosadores e a dos Comentadores, o que vemos atualmente é um direito que ainda oferece e baseia respostas para os grandes problemas jurídicos das sociedades hodiernas.

Finalizamos citando o mestre Iglesias (CRUZ, 1984, p. XXIX):

No estamos tan lejos de Roma como parece. Nuestra civilización se alimenta do que olvida, de lo que ignora y de lo que niega. Y se esto es así, toca a los romanistas, por emcima de todo, poner en claro la razón y medida en que el derecho romano puede servir para aliviar las congojas actuales ${ }^{5}$.

\section{REFERÊNCIAS}

ALMEIDA COSTA, Mário Júlio de. História do direito português. 3. ed. Coimbra: Almedina, 2008.

AMBROSINO, Rodolfo. Usus fructus e communio (profilo storico dell'usufrutto) em SDHI 16. Roma: PIUI, 1950.

ASCEnSÃO, José de Oliveira Ascensão. Teoria Geral do Direito Civil. 1. ed. Coimbra: Coimbra, 1995).

BEVILÁCQUA, Clóvis, Teoria geral do direito civil. 2. ed. Rio de Janeiro: Rio, 1980. BETANCOURT, Fernando. Sobre una pretendida "actio" arbitraria contra el usufructuario em AHDE 43. Madri: INEJ, 1973.

BORTOLUCGI, Giovanni. Sulla “cautio usufructuaria” em BIDR 21. Roma: IDR, 1909.

COHEN, Boaz. Ususfructus in Jewish and Roman Law em RIDA 1. Bruxelas: OIL, 1954.

Vale ressaltar que o texto do romanista espanhol foi produzido em 1968, ou seja, faz 42 anos que fora escrito, mas a crítica continua atualíssima. 
CRUZ, Sebastião. Direito Romano (Ius Romanum - Fontes). Coimbra: Dislivro, 1984. GUARINO, Antonio. La nozione romana di usufrutto em Labeo 9. Nápoles: Edit. Univ. Nápoles, 1963.

IGLESIAS, Juan. Derecho Romano - Instituciones de derecho privado. 2. ed. Barcelona: Ariel, 1953.

MASSON, Pierre. Essai sur la conception de l'usufruit en droit romain em RH 13. Paris: LRS, 1934.

MOREIRA ALVES, José Carlos. Direito Romano. 14 ed. Rio de Janeiro: Forense, 2007.

SANTOS JUSTO, A.. Direito Privado Romano I. 3. ed. Coimbra: Coimbra, 2003.

_. Breviáriode Direito Privado (Direitos Reais) - 20Cido. Coimbra: FDUC, 2009. . Direito Privado Romano II. 2 ed. Coimbra: Coimbra, 2006. . Direito Privado Romano III. Coimbra: Coimbra, 1997. . Direito Privado Romano IV. Coimbra: Coimbra, 2008. . Direitos reais. Coimbra: Coimbra, 2007.

SOLAZZI, Siro. La cessione dell'usufrutto em SDHI 16. Roma: PIUI, 1950.

VOLTERRA, Edoardo. Instituzioni di Diritto Privato Romano. Roma: LSE, 1961.

\section{USUFRUCT IN ROMAN AND LUSO-BRAZI LIAN LAWS}

Abstract: This article, produced around the Romanists, will present and analyze briefly the historical and legal aspects relating to the legal institute called usufruct, from its inception and development in Roman law, up to today's Portuguese and Brazilian laws.

Keywords: Usufruct. Roman Law. Portuguese law. Brazilian law. 